\title{
Toxoplasma gondii infection in patients with schizophrenia
}

\begin{tabular}{ccc}
\hline Hawre M. Bakre * & Saeed K.Hussain * & Sirwan K. Ali ** \\
\hline & Abstract
\end{tabular}

Background and objective: Schizophrenia is a complex chronic neuropsychiatric disease of the central nervous system, believed to have multiple etiologies. Toxoplasma gondii has emerged as an interesting candidate as a possible cause of some cases of schizophrenia. As there is scarce information about the seroprevalence of $\mathrm{T}$. gondii infection in psychiatric patients in Erbil; we investigated the seroprevalence of T.gondii in schizophrenic patients and compared with that obtained from control individuals in Erbil correlated with inflammatory marker C-reactive protein.

Methods: This case control study included 93 schizophrenic patients seeking medical advice at Hawler Psychiatric Hospital and private clinics with 93 non psychiatric control were screened for the presence of anti-toxoplasma IgG, IgM (by ELISA test) and C-reactive protein using qualitative methods. A questionnaire was used to collect socio-demographic and behavioral data among the respondents.

Results: In chronic cases anti-Toxoplasma gondii IgG antibodies were seropositive in $30 / 93(32.3 \%)$ of the schizophrenic patients and 4/93(4.3\%) of control $(P<0.001)$. The seropositive rate of $\operatorname{lgM}$ antibodies was $9.7 \%$ and $1.1 \%$ among schizophrenic patients and control, respectively $(P=0.006)$. The result of $C$-reactive protein positivity among patients and control was $23.6 \%$ and $3.22 \%$, respectively $(P<0.001)$.

Conclusion: Our results delineate that association might exist between Toxoplasma gondii infection and schizophrenia etiology.

Keywords: Toxoplasmosis, Toxoplasma gondii, Schizophrenia, C-reactive protein.

\section{Introduction}

Toxoplasma gondii is an obligate intracellular protozoan parasite belong to phylum Apicomplexa. ${ }^{1}$ Toxoplasma gondii is a protozoan parasite found worldwide, ${ }^{2}$ that infects all kinds of mammals, including cats, livestock, and human beings. In its life cycle, cats and other felids are the definitive hosts and the other warm-blooded vertebrates are intermediate hosts. ${ }^{3}$ Human infections with Toxoplasma gondii occur mainly by ingesting food or water contaminated with oocyst or eating undercooked or raw meat containing tissue cyst. ${ }^{4}$ The role of coccidian protozoa Toxoplasma gondii represents one of the most enigmatic and unexplained questions in the field of pathophysiology of schizophrenia. Toxoplasma gondii is a very successful parasite, infecting approximately $30 \%$ of the human population. ${ }^{5}$ The congenital toxoplasmosis is linked to severe neuropsychiatric and ophthalmological symptoms. ${ }^{6}$ A variety of brain cells including astrocytes and neurons can be infected. It is proposed that neurotropic cysts of toxoplasma exert an effect on animal behavior, either directly or via release of metabolic products. Long standing infection in humans has been linked to cerebral tumor formation and personality shift. ${ }^{7}$ Schizophrenia is a progressive neuropsychiatry disease of uncertain cause that approximately affects $1 \%$ of the adult population in USA and Europe. There is a clear inheritable

* Department of microbiology, college of medicine, Hawler medical university, Erbil, Iraq.

$* *$ Department of psychiatry, college of medicine, Hawler medical university, Erbil, Iraq. 
http://dx.doi.org/10.15218/zjms.2015.0006

component, but familial incidence is sporadic and schizophrenia does occur in families with no history of the disease. ${ }^{8}$ Schizophrenia is widely believed to have a neurobiological basis. The most notable theory is the dopamine hypothesis, which posits that schizophrenia is due to hyperactivity in brain dopaminergic pathways. ${ }^{9}$ Some researchers have found an association between some cases of schizophrenia and toxoplasmosis. Toxoplasmosis can lie dormant in the nervous system and migrate to the brain over many years. Some cases of acute toxoplasmosis in adults are associated with psychiatric symptoms such as delusions and hallucinations. ${ }^{10}$ Toxoplasma gondii genome is known to contain two aromatic amino acid hydroxylases that potentially could directly affect dopamine and/or serotonin biosynthesis. ${ }^{9}$ However, stimulation of the immune response has also recently been associated with mood and behavioral alterations in humans, and compounds designed to alter mood, such as fluoxetine, have been demonstrated to alter aspects of immune function. Herein, the evidence for Toxoplasma gondii induced behavioral changes relevant to schizophrenia and depression is reviewed. ${ }^{11}$ The activity of the immune system is likely to play an important role in many of the observed effects of Toxoplasma infection. Thus, the impairment of the immune system has been suggested to be at least partly responsible for the observed association between toxoplasmosis and schizophrenia. $^{12}$ Many of the observed behavioral effects of toxoplasmosis might be a result of the increased level of dopamine in the brain tissue in response to IL-2 produced by immune cells in the sites of local inflammation in the infected brain. ${ }^{13,14}$ Toxoplasma gondii has been identified as a candidate infectious agent related to schizophrenia. ${ }^{8}$ A study has revealed that newborns who have antibodies to Toxoplasma gondii have an increased risk of later being diagnosed with schizophrenia. ${ }^{15}$ Apart from that, environmental factors such as infections with Toxoplasma gondii is found to be more frequent in individuals with schizophrenia than in psychiatrically healthy controls. ${ }^{16}$ To investigate possible associations between Toxoplasma gondii infection and schizophrenia, we assessed the seroprevalence of anti-Toxoplasma gondii $\operatorname{lgG}$ and $\operatorname{lgM}$ antibodies in individuals with schizophrenia and disease free group as control subjects; together with the assessment and evaluation of role of inflammatory marker C-reactive protein (CRP).

\section{Methods}

\section{Studied groups}

Serum samples were collected from 93 patients (36 females and 57 males) admitted to Hawler Psychiatric Hospital in Erbil. Diagnosis was made by psychiatrists and confirmed by diagnostic and statistical manual of mental disorders, fourth edition (DSM-IV). ${ }^{17}$ The mean ( \pm SD) age was $34 \pm 53$. On clinical ground and laboratory investigations were carried out, 20 were recently diagnosed as acute schizophrenic cases. The other 73 patients were under antipsychotic therapy (chronic cases).

A matched age and gender control group consisted of 93 healthy volunteers was chosen who had no history of schizophrenia. They were also tested for toxoplasmosis as a control. The patient and controls were living in the urban and rural region in and near Erbil city.

\section{Serological technique}

Five millimeters of blood was taken from 93 schizophrenic patients and 93 controls under sterile conditions. Serum sample were obtained by centrifugation at (3000 rpm for $10 \mathrm{~min}$ ) of blood collected from the participants and kept at $-20^{\circ} \mathrm{C}$ pending ELISA tests. Serum samples were assayed for latex agglutination test, anti-T.gondii IgG and IgM antibodies with a commercially ELISA kit and qualitative method for C-reactive protein. All tests were performed following the instructions of the manufacturer. The patients' demographic data such as age, gender, 
ethnic, duration of disease, family history of schizophrenia and number of hospitalization due to schizophrenia were taken. Informed consent was taken from patients prior to the blood taking.

\section{Ethical Consideration}

This study was approved by the Research Ethics Committee of Hawler Medical University/College of Medicine, Erbil. All participants were provided with written informed consent after the study purpose and procedures were explained.

\section{Statistical analysis}

Statistical analysis was done by using statistical package for the social sciences (version 19.0). The relative proportions were calculated with a confidence interval of $95 \%$. Possible associations were identified using the Chi-square and Fisher's exact statistical tests at a significant level $\mathrm{P} \leq 0.05$.

\section{Results}

The baseline of control and schizophrenic patients regarding the type of clinical presentation as acute or chronic is shown in Table 1. In males, $13 / 57(22.8 \%)$ and $44 / 57(77.2 \%)$ of cases were diagnosed as acute and chronic cases, respectively. In female, 7/36 (19.4\%) and 29/36 (80.6\%) were diagnosed as acute and chronic case, respectively. The control schizophrenia free subjects included 49 males and 44 females with age range apparently compatible with schizophrenia cases. The results of serologic finding are summarized in Table 2 using Toxoplasma latex test and anti-Toxoplasma IgM and IgG by means of ELISA test. Thus $44.1 \%$ and $12.9 \%$ of cases and control showed Toxoplasma seropositivity when using direct Toxoplasma latex test and the result was highly significant $(P<0.001)$. ELISA anti-toxoplasma IgM test on the other hand revealed seropositivity in $9.7 \%$ and $1.1 \%$ of cases and control, respectively $(P<0.006)$. Meanwhile ELISA anti-toxoplasma IgG was positive in $32.3 \%$ and $4.3 \%$ of schizophrenic patients and control group, respectively $(P<0.001)$. The difference between anti-toxoplasma $\operatorname{lgM}$ and $\lg G$ was highly significant $(P<0.001)$.

Table 1: Base line characteristic of schizophrenic patients and control group

\begin{tabular}{|c|c|c|c|c|c|c|}
\hline \multirow[b]{2}{*}{ Group } & \multicolumn{3}{|c|}{ Schizophrenic patients } & \multirow[b]{2}{*}{$\begin{array}{l}\text { Age } \\
\text { (Mean } \pm S D)\end{array}$} & \multicolumn{2}{|l|}{ Control } \\
\hline & $\begin{array}{l}\text { Total } \\
\text { No (\%) }\end{array}$ & $\begin{array}{l}\text { Acute Cases } \\
\text { No (\%) }\end{array}$ & $\begin{array}{l}\text { Chronic Cases } \\
\text { No }(\%)\end{array}$ & & $\begin{array}{l}\text { Total } \\
\text { No (\%) }\end{array}$ & $\begin{array}{l}\text { Age } \\
\text { (Mean } \pm S D)\end{array}$ \\
\hline Male & 57 & $13(22.8 \%)$ & $44(77.2 \%)$ & $34 \pm 53$ & 49 & $33 \pm 68$ \\
\hline Female & 36 & $7(19.4 \%)$ & $29(80.6 \%)$ & $35 \pm 23$ & 44 & $34 \pm 25$ \\
\hline Total & 93 & $20(21.5 \%)$ & 73(78.5\%) & & 93 & \\
\hline
\end{tabular}

Table 2: Anti-Toxoplasma antibodies seropositivity in schizophrenic patients and control group

\begin{tabular}{|c|c|c|c|c|c|c|c|}
\hline \multirow[b]{2}{*}{ Group } & \multicolumn{3}{|c|}{ Toxoplasma latex } & \multicolumn{2}{|c|}{$\begin{array}{l}\text { Anti-Toxoplasma IgM } \\
\text { (ELISA) }\end{array}$} & \multicolumn{2}{|c|}{$\begin{array}{l}\text { Anti-Toxoplasma } \\
\text { IgG (ELISA) }\end{array}$} \\
\hline & $\begin{array}{l}\text { Total } \\
\text { No. }\end{array}$ & $\begin{array}{l}\text { +ve } \\
\text { (o) }\end{array}$ & $\begin{array}{l}\text {-ve } \\
\text { No (\%) }\end{array}$ & $+\mathrm{ve}$ & $\begin{array}{l}\text {-ve } \\
\text { No (\%) }\end{array}$ & $\begin{array}{l}+\mathrm{ve} \\
\mathrm{No}(\%)\end{array}$ & $\begin{array}{l}\text {-ve } \\
\mathrm{No}(\%)\end{array}$ \\
\hline Schizophrenic & 93 & $41(44.1 \%$ & $52(55.9 \%)$ & $9(9.6 \%)$ & 84 (90.3\%) & $30(32.3 \%)$ & $63(67.7 \%)$ \\
\hline Control & 93 & 12 (12.9) & $81(87.1)$ & $1(1.1 \%)$ & 92(98.9\%) & $4(4.3 \%)$ & $89(95.7 \%)$ \\
\hline \multicolumn{8}{|c|}{$\begin{array}{lc}\text { Toxo-latex agglutination } & P<0.001 \\
\text { Anti-Toxoplasma IgM (ELISA): } & P=0.006 \text { (acute cases) } \\
\text { Anti-ToxoplasmalgG (ELISA): } & P<0.001 \text { (chronic cases) } \\
\text { Anti-Toxoplasma lgM and IgG ( ELISA) : } P<0.001\end{array}$} \\
\hline
\end{tabular}


Table 3 reveals the number and percent distribution of patients and control seropositive and negative for inflammatory marker namely CRP using qualitative method. Thus CRP seropositive sera was detected in $23.7 \%$ and $3.2 \%$ of schizophrenic cases and control, respectively $(P<0.001)$. The difference between schizophrenia and control groups highly significant for CRP $(P<0.001)$.

Table 3: C_ reactive protein positivity in control and schizophrenic patients

\begin{tabular}{lll}
\hline \multirow{2}{*}{ Group } & \multicolumn{3}{l}{ C-reactive protein status } \\
& + Ve (\%) & -Ve (\%) \\
\hline \multirow{2}{*}{ Schizophrenia } & $22(23.7 \%)$ & $71(76.3 \%)$ \\
Control & $3(3.2 \%)$ & $90(96.8 \%)$ \\
\hline
\end{tabular}

\section{Discussion}

Toxoplasma gondii is highly neurotropic that affecting both neurons and glia in brain. ${ }^{18}$ These later cells are also target in the pathophysiology of schizophrenia ${ }^{19-21}$ that subsequently affecting brain neurotransmitters. This study possibly could be the first in Iraqi Kurdistan region that seek the association between $T$. gondii and schizophrenia as a possible etiologic parasitic factor in some cases. The present study has demonstrated anti-T. gondii seropositivity in schizophrenic patients when compared with control group using Toxoplasma latex; anti-T. gondii IgM by ELISA $(P<0.006)$ and anti-T. gondii IgG. On clinical ground anti-T. gondii $\lg M$ and IgG seropositive cases might reflect possibly acute and chronic schizophrenic cases respectively. ${ }^{2}$ The findings of our study replicate the results of same recent studies that have shown a higher significant anti-T. gondii $\lg$ antibodies in schizophrenic when compared with control. ${ }^{11,2,10,18,22}$ However, they disagree with other studies who report no significant difference between patients and control for anti-T. gondii $\operatorname{lgG} .^{3},{ }^{23}$ For anti-T. gondii $\operatorname{lgM}$, the results of the present study disagree with other studies who report no significant difference between schizophrenic patients and control. ${ }^{1,3,18,24}$ $\mathrm{T}$. gondii has emerged as a prime candidate etiologic factor in some cases of schizophrenia for a variety of reasons. ${ }^{19}$ Of these, (i) many studies have reported a higher prevalence of $\mathrm{T}$. gondii antibodies in sera of schizophrenic patients compared with control, (ii) some peoples with adult toxoplasmosis develop psychotic symptoms similar to those of schizophrenia, (iii) epidemiologically the existence of many similarities between toxoplasmosis and schizophrenia, (iv) antipsychotic drugs can also inhibit T.gondii, (v) elevated level of dopamine in commonly seen in schizophrenic patients that coincide with elevated level of dopamine experimental animal infected with $T$. gondii (vi) schizophrenic patients when compared with control have had a greater exposure to cats in children. ${ }^{25}$ Since 25 original studies in $1953,,^{19,20} 54$ similar studies have been reported for the line between $T$. gondii and psychoses. Of these 54 studied, 42 have been reviewed in 2007 included a meta-analysis of 23 of them in which the odds ratio of having $T$. gondii with a diagnosis of schizophrenia was $2.73 .^{16,19}$ It is well known that schizophrenic patients have abnormal neurotransmitters namely dopamine, glutamate and gammaAminobutyric acid (GABA). ${ }^{18,19}$ The link between $T$. gondii and dopamine, is the fact that $T$. gondii harbor two genes that encode forms of tyrosine hydroxylase; the enzyme vital in the generation of dopamine in the brain. ${ }^{9,19}$. Epidemiologically, there are at least seven areas of similarity between toxoplasmosis and schizophrenia; of these, age of onset and gender, beside two epidemiologic dissimilar aspects. In this study male was higher than female as schizophrenia incidence or prevalence. Our results agree with other studies. ${ }^{19,26}$ Schizophrenia may be associated with inflammatory reaction and CRP as one of the inflammatory marker is a nonspecific serum protein that reflect persistent 
http://dx.doi.org/10.15218/zjms.2015.0006

a highly significant difference exist between schizophrenic patients (23.7\%) and healthy control (3.2\%) seropositivity for the inflammatory marker CRP $(P \leq 0.001)$ using qualitative method. Our results agree with other studies. ${ }^{27-30}$ Antipsychotic effects on CRP have received little attention as different antipsychotics drugs may have differential effects on CRP level particularly after three months of treatment. ${ }^{31}$ Elevated serum level of CRP in schizophrenia are associated with the severity of cognitive impairment but not of psychiatric symptom. ${ }^{26}$ This is in contrast with a study which reported that patient with elevated CRP had a significantly more severe psychiatric symptom. ${ }^{29}$ Of antipsychotic, haloperidol significantly increased CRP level during the first three months of treatment. After three months of treatment, CRP level using haloperidol was $92.7 \%$ higher than those in risperidone patients. ${ }^{31}$ Thus, the contribution of various antipsychotic (via increasing CRP level) to coronary heart disease may differ in their influence on metabolic syndrome by increasing the risk of obesity; directly increasing lipid level and directly increasing glucose level. ${ }^{31-33}$

\section{Conclusion}

The high seropositivity of anti- $T$. gondii IgM and IgG among schizophrenic patient reflects a possible role of this parasite in the pathophysiology and etiology of schizophrenia; supported with increased inflammatory marker of CRP.

\section{Conflicts of interest}

The author reports no conflicts of interest.

\section{References}

1. Juanah L Y, Jalaludin J, Osman M, Osman ZJ. Seroprevalence of Toxoplasma gondii among schizophrenics at hospital kajang. Am J Infec Dis 2013; 9 (1):11-6.

2. Alvarado-Esquivel C, Estrada-Martinez S, PizrroVillalobos $\mathrm{H}$, Arce-Quinones M. Seroepidemiology of Toxoplasma gondii infection in general population in a northern Mexican city. J Parasitol 2011; 97:40-3.

3. Daryani A, Sharif M, Hosseini $S H$, Karimi SA,
Gholami S. Serological survey of Toxoplasma gondii in schizophrenia patients referred to psychiatric hospital Sari city. Iran Tropical Biomedicine 2010; 27(3):476-82.

4. Dubey JP, Jones JL. Toxoplasma gondii infection in humans and animals in the United States. Int $\mathrm{J}$ Parasitol 2008; 38:1257-78.

5. Jones JL, Kruszon-Moran D, Wilson M, McQuillan G, Navin T, and McAuley JB. Toxoplasma gondii infection in the United States: seroprevalence and risk factors. Am J Epidemiol 2001; 154:57-65.

6. Carruthers VB, Suzuki Y.Toxoplasma gondii infection on the brain. Schizophr Bull 2007; 33:745-51.

7. Holiman RE. Toxoplasmosis, behavior and personality. J Infect Dis 1997; 35:105-10.

8. Torrey EF, Yolken, RH. Toxoplasma gondii and schizophrenia. Emerg. Infect Dis 2003; 9:1375-80.

9. Gaskell EA, Smith JE, Pinney JW, Westhead DR, McConkey GA. A unique dual activity amino acid Mahmoud hydroxylase in Toxoplasma gondii. Plos One 2009; 4: e4801. 161-72.

10. Mahmoud SS, Hasan MS. Seroprevalence of toxoplasmosis among Schizophrenic patients. Yemeni J Med Sci 2009; 1(3):67-773

11. Webster JP, McConkey GA. Toxoplasma gondii-altered host behaviour: clues as to mechanism of action. Folia Parasitologica Praha 2010; 57:95-104

12. Flegr J. Effects of Toxoplasma gondii on human behavior. Schizophr Bull 2007: 33:757-60.

13. Novotná $M$, Hanušová $J$, Klose $J$, Preiss $M$, Havlicek J, Roubalova K, et al. Probable neuroimmunological link between Toxoplasma and cytomegalovirus infections and personality changes in the human host. BMC Infect Dis 2005; 5:54.

14. Hodková H, Kodym P, Flegr J. Poorer results of mice with latent toxoplasmosis in learning tests: impaired learning processes or the novelty discrimination mechanism. Parasite 2007; 134:1229-337.

15. Mortensen PB, Nørgaard B, Waltoft BL. Toxoplasma gondii as a risk factor for early-onset schizophrenia: analysis of filter paper blood samples obtained at birth. Biol Psychiatry 2007; 61:688-93.

16. Torrey EF, Bartko JJ, Lun ZR, Yolken RH. Antibodies to Toxoplasma gondii in patients with schizophrenia :a meta-analysis. Schizophr Bull 2007; 33:729-36.

17. Sheehan D, Janavs J, Harnett-Sheehan K, Sheehan M, Gray C. Mini International Neuropsychiatric Interview (MINI) 2009 English version 6.0.0 DSM-IV.

18. Hamidinejat $H$, Ghorbanpoor $M$, Hossein $H$. Toxoplasma gondii infection in first-episode and inpatient individuals with schizophrenia. Inter J Infec Dis 2010; 14:978-81.

19. Yolken RH, Dickerson FB, Torrey EF. 
Toxoplasma and schizophrenia. Parasite Immunol 2009; 31:706-15.

20. Amminger GP, McGorry PD, Berger GE. Antibodies to infectious agents in individuals at ultra-high risk for psychosis. Biol Psychiatry 2007; 61:1215-7.

21. Schwarcz R, Hunter CA. Toxoplasma gondii and schizophrenia: linkage through astrocyte-derived kynurenic acid. Schizophr Bull 2007; 33:652-3.

22. Alipour A, Shojaee S, Mohebali M, Tehranidoost M, Abdi MF.Toxoplasma infection in schizophrenia patients:A comparative study with control group. Iran J Parasitol 2011; 6:31-7.

23. Emelia O, Amal RN, Ruzanna ZZ, Shahida H, Azzubair Z, Tan KS. Seroprevalence of anti-Toxoplasma gondii IgG antibody in patients with schizophrenia. Trop Biomed 2012; 29(1): 151-9.

24. Saraei SM, Shamloo F, Jahani HH, Khabba F, Alizade SA. Relation between Toxoplasma gondii infections and schizophrenia. Iranian J Psychiatr Clin Psychol 2009; 15(1):3-9.

25. Kozar Z. toxoplasmosis among the mentally sick. Bull Inst Med Mar Trop Gdansk.1953; 5:146-73.

26. Dickerson F, Stallings C, Origoni A, Boronow J, Yolken R. C-reactive protein is associated with the severity of cognitive impairment but not of psychiatric symptoms in individuals with schizophrenia. Schizophr Res 2007; 93:261-6.

27. Beverley JK, Fleck DG , Kwantes W. Age-sex distribution of various diseases with particular reference to toxoplasmic lymphadenopathy. J Hyg (Camb) 1976; 76:215-8.

28. Akanji AO, Ohaeri JU, Al-Shammri S, Fatania HR. Association of blood levels of C-reactive protein with clinical phenotypes in Arab schizophrenic patients. J Phys 2009; 56-61.

29. Fan X, Pristach C, Liu EY, Freudenreich O, Henderson DC, Goff DC. Elevated serum levels of C-reactive protein are associated with more severe psychopathology in a subgroup of patients with schizophrenia. Psychiatry Res 2007;149: 267-71.

30. Mazzarello V, Cecchini A, Fenu G, Rassu M, Dessy LA, Lorettu L, et al. Lymphocytes in schizophrenic patients under therapy: serological, morphological and cell subset findings. Ital J Anat Embryol 2004; 109: 177-88.

31. Diaz FJ, Iglesias PR, Mata I, Garcia OM. Possible effects of some antipsychotic drugs on C -reactive protein in a drug-naive psychotic sample. Schizophr Res 2010; 207-12

32. de-Leon J, Dia Fj. Planning for optimal design of studies to personalize antipsychotic prescriptions in the post-CATIL era: the clinical and pharmacoepidemiological data suggest the pursuing the pharmacogenetics of metabolic syndrome complications (hypertension, diabetes mellitus and hyperlipidemia) may be a reasonable strategy. Schizophr.Res 2007: 96; 185-97.
33. Meyer JM, Stahi SM. The metabolic syndrome and schizophrenia. Acta Psychiatr Scand 2009; 119:4-14. 